\title{
TENS AND LOW-LEVEL LASER THERAPY IN THE MANAGEMENT OF TEMPOROMANDIBULAR DISORDERS
}

\author{
APLICAÇÃO DE TENS E LASER DE BAIXA FREQÜÊNCIA NO TRATAMENTO DAS \\ DISFUNÇÕES TEMPOROMANDIBULARES
}

Melissa Thiemi KATO ${ }^{1}$, Evelyn Mikaela KOGAWA ${ }^{2}$, Carlos Neanes SANTOS ${ }^{3}$, Paulo César Rodrigues CONTI ${ }^{4}$

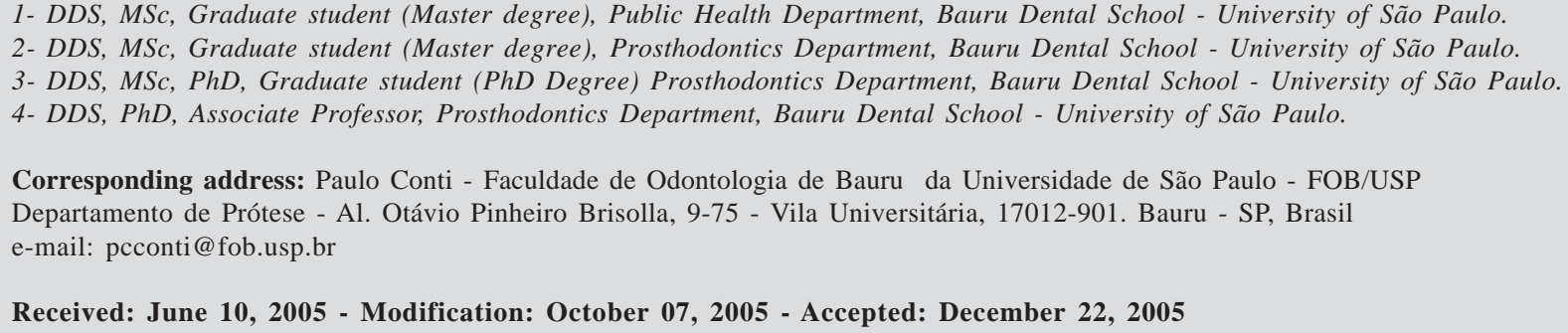

Received: June 10, 2005 - Modification: October 07, 2005 - Accepted: December 22, 2005

\begin{abstract}
$P$

$P_{\text {ain relief and reestablishment of normal jaw function are the main goals of conservative management of Temporomandibular }}$ Disorders (TMD). Transcutaneous electrical nerve stimulation (TENS) and laser therapy are part of these modalities, although little is known about their real efficacy in controlled studies. This research compared these two treatments in a sample of 18 patients with chronic TMD of muscular origin, divided into two groups (LASER and TENS). Treatment consisted of ten sessions, in a period of 30 days. Active range of motion (AROM), visual analogue scale (VAS) of pain and muscle (masseter and anterior temporalis) palpation were used for follow-up analysis. Data were analyzed by Friedman test and ANOVA for repeated measurements. Results showed decrease in pain and increase in AROM for both groups $(p<0.05)$, and improvement in muscle tenderness for the LASER group. Authors concluded that both therapies are effective as part of TMD management and a cumulative effect may be responsible for the improvement. Caution is suggested when analyzing these results because of the self-limiting feature of musculoskeletal conditions like TMD.

Uniterms: Temporomandibular joint disorders; Physical therapy.
\end{abstract}

\begin{abstract}
RESUMO
$O$

tratamento das Disfunções Temporomandibulares (DTM) objetiva ser conservador e reversível para alívio da dor e restauração da função normal. Sendo assim, tratamentos como a estimulação neural elétrica transcutânea (TENS) e o laser de baixa freqüência têm sido utilizados. Portanto, foi premissa deste trabalho a comparação do TENS com o a terapia com laser de baixa freqüência no tratamento de pacientes com DTM. Foram selecionados dezoito pacientes com sinais e sintomas de DTM crônica de origem muscular. O grupo LASER recebeu aplicação de laser e o grupo TENS, estimulação elétrica, totalizando 10 sessões, três vezes por semana, durante um mês. A avaliação foi feita imediatamente antes e 5 minutos após cada sessão terapêutica, por meio da escala de análise visual (EAV) para o registro da sensação de dor mensuração de abertura máxima e palpação muscular ( masseter e temporal anterior). Para análise estatística foram utilizados o teste de Friedman e ANOVA para mensurações repetidas. Os resultados demonstraram decréscimo na EAV e aumento da abertura bucal máxima de ambos os grupos $(\mathrm{p}<0,05)$. A palpação muscular apresentou diferença significante para o grupo LASER $(\mathrm{p}<0,05)$. Baseado na análise da EAV e movimentação ativa, concluiu-se que ambas as terapias propostas foram efetivas no tratamento das DTM, sendo que o efeito acumulativo pode ser o responsável pela melhora obtida. Porém, é sugerida cautela quando se analisa o presente resultado, devido ao aspecto auto-limitante das condições músculo-esqueletais como as DTMs.

Unitermos: Disfunção temporomandibular; Fisioterapia; TENS; Laserterapia.
\end{abstract}




\section{INTRODUCTION}

Temporomandibular Disorders (TMD) comprise a number of signs and symptoms affecting the masticatory muscles, Temporomandibular Joint (TMJ), or both ${ }^{23}$. Even though they have been subject of study for a long time, many controversies still remain regarding their etiology, diagnosis, and treatment. TMD etiology is currently known to be multifactorial, including the presence of parafunctional habits, trauma, stress, and emotional, systemic, hereditary, and occlusal factors. Nevertheless, none of these factors has demonstrated to overcome the others.

Based on the multifactorial etiology of such problems, the treatment usually involves more than one modality in order to maximize any complementary effects, including counseling, drug therapy and physical therapy.

In this context, physical therapy aims to a) increase the awareness of the patient about the cause of the symptoms; b) achieve muscle relaxation; c) reduce muscular hyperactivity and reestablish muscle and joint movement; d) relieve pain, spasm, and edema; and e) allow for recovering of normal function. Among such treatments, acupuncture, exercises, massages, thermal therapy, electric stimulation (TENS), ultrasound, and low level laser have been used.

Some of these methods were already evaluated and contradictory outcomes were observed regarding treatment effectiveness in TMD.

TENS is regularly employed in patients with $\mathrm{TMD}^{29}$, in view of its analgesic and muscle relaxing effect, with positive results $^{12}$. Bassanta, Sprosser and Paiva ${ }^{2}$, in 1997, conducted TENS therapy in 26 patients presenting signs of myofascial dysfunction, limited mouth opening and pain or tenderness in the temporalis and masseter muscles bilaterally. Through electromyographic and eletrognathographic analysis, the authors concluded that the treatment promoted muscle relaxation and reduced the pain sensation.

There are many papers reporting the use of LLLT (low level laser therapy) for improvement of symptomatology of TMD patients ${ }^{20}$. In 1988, Bezuur, Habets, Hansson ${ }^{4}$ observed total pain relief in $80 \%$ of arthrogenic patients (TMJ) after delivery of LLLT for a mean period of 6 days. Hansson ${ }^{16}$, in 1989, reported a fast decrease in intra-articular inflammation in TMJ of five patients after application of infrared laser. In 1989, Hatano ${ }^{17}$ observed positive effects of laser radiation for reduction of the patient's responses to palpation with an 830nm device, but this study did not include a control group. On the other hand, Hanssen, Thoroe ${ }^{15}(1990)$, carried out a double-blind study to evaluate the effectiveness of an invisible infrared laser diode (904nm) for therapy of orofacial pain and no significant differences were found for the VAS between the control and experimental groups. Gam, Thorsen, Lonnberg $^{10}$, in 1993, observed the effect of low level laser therapy in a meta-analysis and concluded that such treatment is not effective for musculoskeletal disorders. Conti ${ }^{6}$, in 1997, evaluated the efficacy of low level laser therapy in patients with TMD by means of a double-blind design and the outcomes did not demonstrate significant differences between the real and placebo groups.
The literature demonstrates the importance of physical therapy in the treatment of Temporomandibular Disorders ${ }^{8}$. Therefore, the aim of this study was to compare the effectiveness of Transcutaneous eletric nerve stimulation (TENS) and low-level laser therapy for the treatment of patients with chronic myogenic TMD.

\section{MATERIALAND METHODS}

\section{Subjects}

Although a total of 20 subjects were initially included, two abandoned the study for different reasons. Final sample was composed of 18 individuals (with a mean age of 25.6 years) attending the TMD and Orofacial Pain Center of the Department of Prosthodontics of Bauru Dental School, University of São Paulo (Table 1). Patients presenting with more than 5 posterior missing teeth (except for third molars) or other occlusal risk factors for TMD were excluded. Patients were randomly selected and proportionally divided into two groups, namely LASER group and TENS group. Before three days and during the course of this study, patients were asked not to take analgesic drugs, or have other form of therapy, including palliative home care, counseling or muscle exercises.

The entire sample was informed about the objectives of the study and after all procedures had been explained, an informed consent term, in agreement with the regulation \#196/96 of the Brazilian National Health Council, was signed.

Inclusion was performed after anamnesis and detailed physical examination, including muscle and TMJ palpation, evaluation of the mandibular movements and joint sounds. Individuals presenting signs and symptoms of pain on the masticatory muscles (temporal and masseter) were included. Subjects with muscle tenderness caused by systemic diseases, dental-related pain, or patients with psychological disturbances were also excluded, as well as those with any restriction for the employment of electrical therapy.

\section{Examiners}

The research coordinator applied the laser therapy, while TENS was applied by a general practitioner. Another researcher carried out the selection of patients and coordination of the project in order to establish a doubleblind design. Moreover, a specialized dentist conducted the physical evaluation of the patients before and after treatment sessions.

\section{Devices}

A low level laser device with wavelength of 830 to $904 \mathrm{~nm}$ was used at an output of $4 \mathrm{~J} / \mathrm{cm}^{2}$ and power of $100 \mathrm{~mW}$ (VRkc-610 SOFT LASER - Dentoflex, São Paulo -SP, Brazil). For the transcutaneous electric stimulation (TENS), the selected device was the Myomonitor BNS-40 (Myotronics, Seattle, USA), which emits a low level electric pulse rhythmically every $1.5 \mathrm{sec}$, together with surface electrodes Myo-trodes II (Myotronics, Seattle, USA). 


\section{Treatment modalities}

The application techniques followed the manufacturers' instructions. The LASER group was submitted to the low level laser therapy with "scanning" movements instead of touching the skin directly over the painful area. This technique was suggested by the manufacturer and allows for treating not only a limited painful spot, but the entire painful area by means of this "scanning" motion.

The period of application for this group was 9 minutes for each side of the face.

The TENS group received the same number of sessions as the LASER group, comprising 10 sessions, 3 times a week, during 4 weeks.

The total time of application of this therapy was 40 minutes, excluding the first 5 minutes.

\section{Evaluation}

Evaluation was performed immediately before and 5 minutes after each therapeutic session by means of the visual analogue scale (VAS), mandibular active range of motion (AROM) and palpation of the masticatory muscles.

The VAS is carried out through a horizontal line measuring $100 \mathrm{~mm}$, containing the text "no pain" at the left end and "the worst possible pain" at the right end, on which the patient marks, through a vertical line, the position that better indicates the degree of perceived pain at that moment. Such measurement constitutes a parameter for subjective follow-up of the evolution of symptoms.

Muscle palpation was performed bilaterally, with firm yet gentle and constant pressure of approximately 1500 grams, as described by Conti, et al.?

Thus, on the basis of the reactions demonstrated by individuals, the degree of pain under palpation was rated as 0 - no pain; 1 - mild pain; 2 - moderate pain; 3 - severe pain.

The evaluated muscles were the masseter and the anterior portion of the temporalis muscle.

\section{Statistical analysis}

The Friedman test for intragroup analysis and the 3-way ANOVA for repeated measurements evaluated possible differences between groups (TENS X LASER), between before and after each session (immediate effect) and between sessions. Differences below 5\% $(\mathrm{p}<0.05)$ were considered statistically significant.

\section{RESULTS}

Evaluation of the Visual Analogue Scale (VAS)

Initial VAS for the LASER group was $66.1 \mathrm{~mm}$ and final VAS of $7.8 \mathrm{~mm}(\mathrm{p}<0.001)$. For the TENS group, initial VAS was $57.2 \mathrm{~mm}$ and final VAS was $4.4 \mathrm{~mm}(\mathrm{p}<0.019)$.

Treatment evolution can be seen in Figure 1, where a general improvement before and after each session can be observed. Besides, it is noticed that the posterior session begins with a milder pain the anterior session.

The outcomes of the VAS highlighted that there was no statistically significant difference between groups ( $\mathrm{p}=0.527$ ), and the immediate effect was also not significant ( $\mathrm{p}=0.266$ ). On the other hand, the effect between sessions (within group analysis) was statistically significant $(\mathrm{p}=0.048)$.

\section{Active range of motion (AROM)}

Figure 2 shows the significant improvement in maximum opening (initial mean of $42.5 \mathrm{~mm}$, being $43 \mathrm{~mm}$ for the LASER group and $42 \mathrm{~mm}$ for the TENS group, and final mean of $47.4 \mathrm{~mm}$, being $47.6 \mathrm{~mm}$ and $47.2 \mathrm{~mm}$ for the LASER and TENS groups, respectively.

The ANOVA demonstrated that there was no statistically significant difference between groups, including the immediate effect ( $\mathrm{p}=0.860$ and $\mathrm{p}=0.091$, respectively). However, a significance difference between sessions was found $(\mathrm{p}<0.001)$.

\section{Muscle palpation}

Statistical analysis (Friedman test) revealed no statistically significant difference regarding pain relief for the anterior temporalis muscle between groups (LASER and TENS ) or between right or left sides (Table 2).

Figures 3 and 4 demonstrate alternation between pain

TABLE 1- Demographic data for each evaluated group

\begin{tabular}{lll}
\hline GROUP & LASER & TENS \\
\hline Gender & 8 female and 1 male & 8 female and 1 male \\
Age (min - max) & 25.8 years $(25-40)$ & 25.4 years $(25-40)$ \\
Pain duration (min-max) & 8 months $(6-24)$ & 10 months $(8-24)$ \\
\hline
\end{tabular}

TABLE 2- Statistical outcomes for muscle palpation of the left and right temporalis muscles for each evaluated group

\begin{tabular}{lll}
\hline GROUP & Right side & Left side \\
\hline LASER & $p=0.237$ & $p=0.607$ \\
TENS & $p=0.187$ & $p=0.094$ \\
\hline
\end{tabular}

TABLE 3- Statistical outcomes for muscle palpation of the left and right masseter muscle for each evaluated group

\begin{tabular}{lll}
\hline GROUP & Right side & Left side \\
\hline LASER & $\mathrm{p}=0.017$ & $\mathrm{p}=0.003$ \\
TENS & $\mathrm{p}=0.311$ & $\mathrm{p}=0.097$ \\
\hline
\end{tabular}


improvement and worsening for the temporalis muscles at the right and left sides, with no evident evolution.

There was no statistically significant difference regarding pain decrease of the masseter muscle for both right and left sides ( $\mathrm{p}=0.312$ and $\mathrm{p}=0.097$, respectively) for the TENS group. However, for the LASER group there was a statistically significant difference for both sides (right and left), yielding $\mathrm{p}<0.001$, respectively. Data can be observed in Table 3.

Figures 5 and 6 demonstrate variation of the pain condition for the masseter muscles at the right and left sides.

\section{DISCUSSION}

Electrical modalities represent additional options in the management of TMD. Aspects related to spontaneous

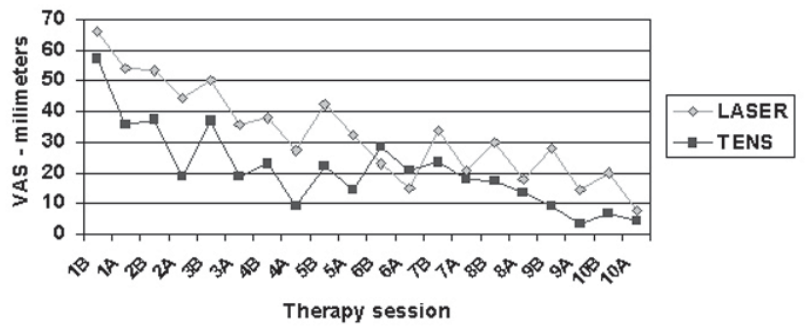

FIGURE 1- Visual analogue scale in millimeters for each evaluated group, before (B) and after (A) each therapeutic session

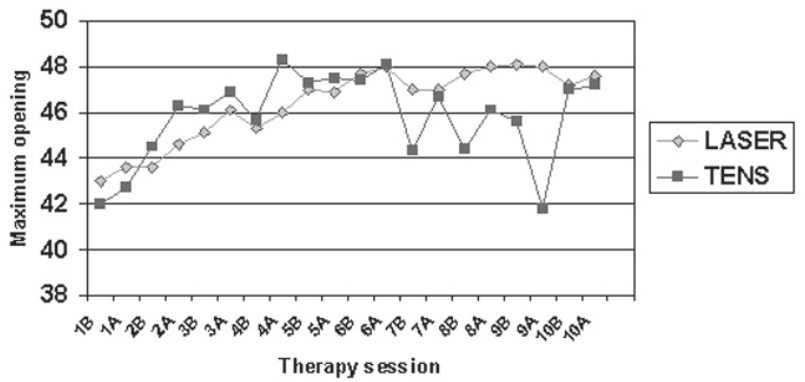

FIGURE 2- Mean maximum opening in millimeters for each evaluated group, before (B) and after (A) each therapeutic session

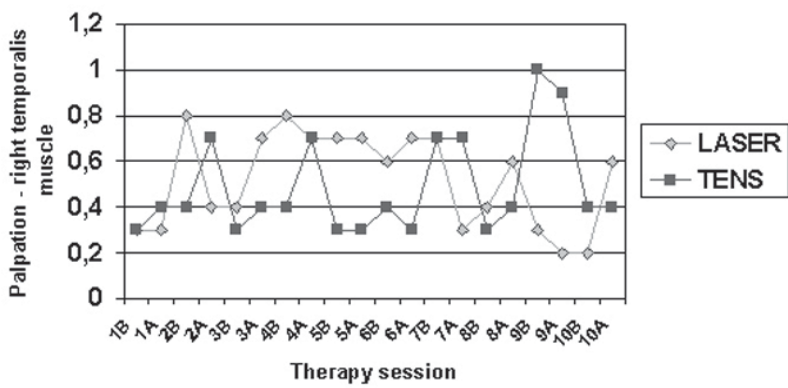

FIGURE 3- Mean palpation of the right temporalis muscle for each evaluated group, before (B) and after (A) each therapeutic session remission of the disease and individual pain perception should be taken into account before the present results are judged. Several criteria are considered for judgment of treatment effectiveness, including mandibular movement, pain scales and ratings of muscle tenderness to palpation.

Mandibular movements allow for a mouth opening up to $60 \mathrm{~mm}$. In adults, 15 to $25 \mathrm{~mm}$ of mouth opening is achieved by means of rotation of the condyle at the inferior border of the disc, measured between the mandibular and maxillary incisors. The remaining range of movement is attributed to the sliding of the condyle-disc complex beyond the fossa, over the articular eminence. In a study conducted by Souza and Guimarães ${ }^{27}$, the mean range of mouth opening of 394 patients, including asymptomatic and symptomatic patients, was $46.29 \mathrm{~mm}$ for the maximum mouth opening (MMO) with a mean age of 34 years, being 326 females (82.75\%) and 68

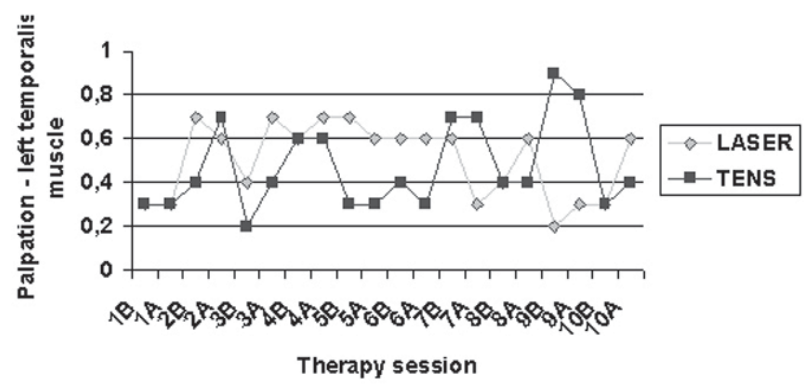

FIGURE 4- Mean palpation of the left temporalis muscle for each evaluated group, before (B) and after (A) each therapeutic session

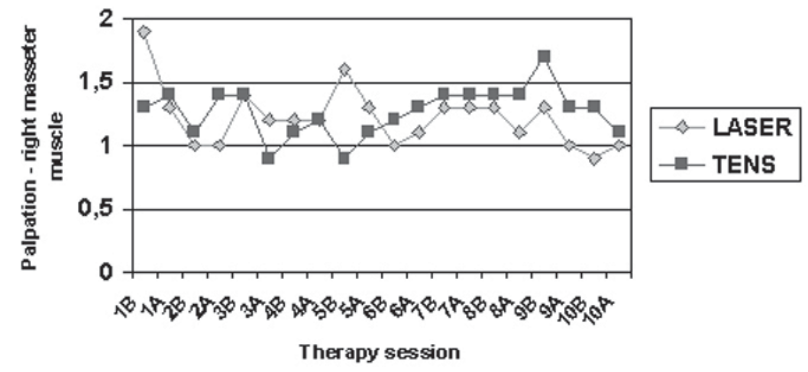

FIGURE 5- Mean palpation of the right masseter muscle for each evaluated group, before (B) and after (A) each therapeutic session

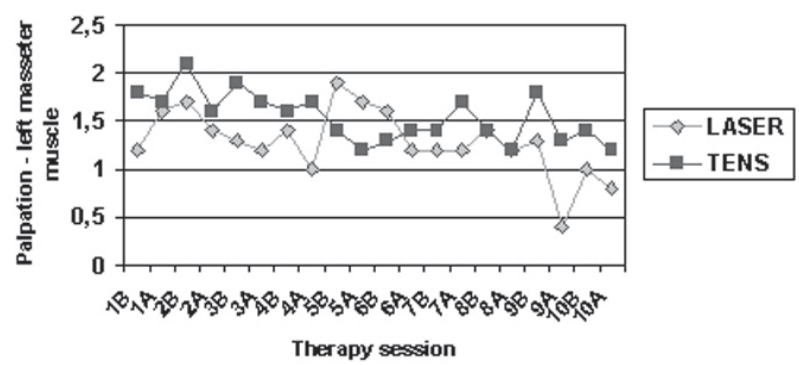

FIGURE 6- Mean palpation of the left masseter muscle for each evaluated group, before (B) and after (A) each therapeutic session 
male (17.25\%). Thirty patients presented limited mouth opening with a mean of $33.13 \pm 1.67 \mathrm{~mm}$. The present study demonstrates that 6 out of the 18 patients (33.33\%), equally distributed between the two groups, presented limited mouth opening before treatment (mean $33.33 \mathrm{~mm}$ ), with a mean of 33mm for the LASER group and 33.66mm for the TENS group. After treatment, the maximum mouth opening increased $10.17 \mathrm{~mm}$ in average, that is, the mean was increased to $43.50 \mathrm{~mm}$, being $42.33 \mathrm{~mm}$ for the LASER group and $44.67 \mathrm{~mm}$ for the TENS group. As expected, the mean range of opening for the individuals presenting with limited mouth opening increased around $10.17 \mathrm{~mm}$ in the average after treatment completion, thus demonstrating that both conservative methods are effective to increase mouth opening, as demonstrated by previous studies ${ }^{5,25}$.

Subjective evaluation of the symptoms by means of the visual analogue scale (VAS) in the present study revealed that, despite the absence of statistically significant differences between the TENS and LASER groups, there was a noticeable improvement of the reported symptoms for both groups, which was statistically significant, especially between sessions (within group analysis). Such outcomes are similar to the study of Gray, et al. ${ }^{13}$

TENS therapy is supposed to stimulate large, fast, myelinated, non-nociceptive neurons in the painful area, "closing the central gate" for those stimuli generated by pain specific fibers. This system, associated to the activation of an endogenous opioid system is supposed to be responsible for the analgesic effect of the TENS.

Nevertheless, the evaluation by means of tenderness to palpation of the temporalis muscle did not show a statistically significant difference for both groups. Alteration between pain decrease and increase on the temporalis muscles at both sides was observed, differently from the results achieved for palpation of the masseter muscle, for which there was a statistically significant difference for both sides (right and left) for the LASER group. LASER activates vasodilatation and stimulates healing, which can account for a positive effect in muscle pain, where hypoxia seems to be a potential excitatory factor for nociceptive first-order neurons.

Some studies have questioned the clinical and biological benefits of the physical therapy in the treatment of musculoskeletal pain ${ }^{10}$. Some researchers believe that there is no scientific evidence demonstrating that the low level laser as applied may reach deep structures ${ }^{26}$. Other authors demonstrate the effectiveness of the low level laser therapy for musculoskeletal disorders ${ }^{3}$, in agreement with the present results.

It is widely accepted that TMD symptoms are fluctuating and self-limiting ${ }^{23}$. It means that many patients will exhibit a natural and expected improvement, even if no therapy is offered. This fact also should be considered when interpreting the actual findings, since a placebo group was not used as control, which is a limitation of the present study.

Basford $^{1}$ in 1989 , criticized the quality of many clinical publications. Even though some authors have questioned the therapeutic effectiveness of these devices ${ }^{3,10,21}$ and the obligatory inclusion of a control group for the test of any treatment modality, it is believed that since TMD patients do not receive any type of therapy other than TENS and laser, the actual findings can be considered acceptable.

The use of TENS has been suggested by many authors for treatment of trigeminal neuropathy, migraine, muscle contraction and TMJ pain ${ }^{14,18,19,22}$. Similar results were obtained in the present study, in which a quite satisfactory outcome was achieved when the report of pain (VAS) was considered.

Several studies also indicate physical therapy for TMD treatment ${ }^{11,23,24,28,30}$. The available literature suggests that physical therapy should be initiated as soon as possible in order to significantly reduce the duration of symptoms ${ }^{9}$. Controlled and longitudinal studies are recommended to evaluate the real validity of electrical therapy in TMD patients and for how long the pain/dysfunction relieve obtained in a short-term study like the present is maintained.

\section{CONCLUSIONS}

Within the limitations of this study, the following conclusions were drawn:

1. Both therapies were effective for decreasing the symptoms of TMD patients, regardless of the type of device used. The cumulative effect may be responsible for this improvement, since it is just observed after several sessions, whereas the immediate effect was not significant.

2. Caution is suggested when analyzing these results, because of the self-limiting aspect of musculoskeletal conditions like TMD. Further clinical studies must be performed to evaluate the real efficacy of physical therapy modalities.

\section{ACKNOWLEDGEMENTS}

This study was supported by FAPESP, BRAZIL, Grant \# 01/00250-0

\section{REFERENCES}

1- Basford JR. Low energy laser therapy: controversies and research findings. Lasers Surg Med. 1989;9:1-5.

2- Bassanta AD, Sprosser JG, Paiva G. Estimulação elétrica neural transcutânea (TENS): sua aplicação nas disfunções temporomandibulares. Rev Odontol Univ São Paulo. 1997;11(2):115 .

3- Beckerman H, de Bie RA, Bouter LM, De Cuyper HJ, Oostendorp RA. The efficacy of laser therapy for musculoskeletal and skin disorders: a criteria-based meta-analysis of randomized clinical trials. Phys Ther. 1992;72:483-91.

4- Bezuur NJ, Habets LLMH, Hansson TL. The effect of therapeutic laser treatment on patients with craniomandibular disorders. J Craniomandib Disord. 1988;2:83-6. 
5- Boschiero R, Fraccari F, Panacco O. Analysis of the results of the use of the Myomonitor in patients with reduced mouth opening. Minerva Stomat. 1986;35:857-64.

6- Conti PCR. Low level laser therapy in the treatment of temporomandibular disorders (TMD): a double-blind pilot study. J Craniomandibular Pract. 1997;15(2):144-9.

7- Conti PCR, Ferreira PM, Pegoraro LF, Conti JV, Salvador MC. A cross-sectional study of prevalence and etiology of signs and symptoms of temporomandibular disorders in High School and University Students. J Orofac Pain. 1996;10(3):254-62.

8- Esposito CJ, Veal SJ, Farman AG. Alleviation of myofascial pain with ultrasonic therapy. J Prosthet Dent. 1984;51:106-8.

9- Friedman MH. Closed lock. A survey of 400 cases. Oral Surg Oral Med Oral Pathol. 1993;75(4):422-7.

10- Gam AN, Thorsen J, Lonnberg F. The effect of low-level laser therapy on musculoskeletal pain: a metal-analysis. Pain. 1993;52:636.

11- Geissler PR, Mc Phee PM. Electrostimulation in the treatment of pain in the mandibular dysfunction syndrome. J Dent. 1986;14:624.

12- Gold N, Greene C, Laskin D. TENS therapy for treatment of MPD syndrome. J Dent Res. 1983;62:244.

13-Gray RJ, Quayle AA, Hall CA, Schofield MA. Physiotherapy in the treatment of temporomandibular joint disorders: a comparative study of four treatment methods. Brit Dent J. 1994;176(7):257-61.

14- Graff-Radford SB, Reeves JL, Baker RL, Chiu D. Effects of transcutaneous electrical nerve stimulation on myofascial pain and trigger point sensitivity. Pain. 1989;37:1-5

15- Hanssen HJ, Thoroe U. Low power laser biostimulation of chronic orofacial pain. A double-blind placebo controlled cross-over study in 40 patients. Pain. 1990;43:169-79.

16- Hansson TL. Infrared laser in the treatment of craniomandibular disorders, artrogenous pain. J Prosthet Dent. 1989;61:614-7.

17- Hatano, Y. Laser in diagnosis of the TMJ problems. Laser in Dentistry. 1989;1:169-72.

18- Hay, K.M. Control of head pain in migraine using transcutaneous electrical nerve stimulation. Practitioner. 1982; 226:771-5.

19- Ihalain U, Perkki L. The effect of transcutaneous nerve stimulation (TENS) on chronic facial pain. Proc Finn Dent Soc. 1978;74:86-9.

20- Kulekcioglu S, Sivrioglu K, Ozcan O, Parlak M. Effectiveness of low-level laser therapy in temporomandibular disorder. Scand J Rheumatol. 2003;32(2):114-8.

21- Mc Donald CJ, Mazzuca SA. How much of the placebo effect is really statistical regression? Stat Med. 1983;2:417-27.

22- Murphy GJ. Utilization of transcutaneous electrical nerve stimulation in managing craniofacial pain. Clin J Pain. 1990;6:64-9.

23- Pertes RA, Gross SG. Clinical management of temporomandibular disorders and orofacial pain. Chicago: Quintessence;1995.

24- Selby A. Physiotherapy in the management of temporomandibular disorders. Aust Dent J. 1985;30:273-80.
25.- Snyder-Mackler L, Bork C, Bourbon B, Trumbore B. Effect of helium-neon laser on musculoskeletal trigger points. Phys Ther. 1986;66:1087-90.

26- Svaasand L. Biostimulering med lav-intensitet lasere. Fysikk eller metafysikk?, Nord Med. 1990;105:72-5.

27- Souza AT, Guimarães JP. Limitação de abertura bucal em pacientes com desordem temporomandibular. Rev Serviço ATM. 2001;1(1):511 .

28- Talaat AM, El Disbany MM, El Garf A. Physical therapy in the management of myofascial pain dysfunction syndrome. Ann Otol Rhinol Laryngol. 1986;95:225-8.

29- Talley RL, Murphy GJ, Smith SD, Baylin MA, Haden JL. Standards for the history, examination, diagnosis and treatment of temporomandibular disorders (TMD): a position paper. J Craniomandibular Pract. 1990;8(1):60-77.

30- Trott PH, Gross AN. Physiotherapist in diagnosis and treatment of the myofascial pain dysfunction syndrome. Int J Oral Surg. 1978;7:360-5. 